\title{
Metode Analitical Hierarchy Process (AHP) Dalam Pemilihan Umum Presiden Indonesia 2019
}

\author{
Evan Rosiska, Rika Harman \\ Universitas Putera Batam, Jln. R. Soeprapto Mukakuning, Batam, 29433, Indonesia.
}

\section{KEYWORDS}

Pemilihan Presiden, Kriteria, Alternatif, AHP, Sistem Pendukung Keputusan.

\section{CORRESPONDENCE}

Phone: +6285266010696

E-mail: evanrosiska29@gmail.com

\section{INTRODUCTION}

Kebanyakan keputusan yang diambil oleh seseorang dalam kehidupan sehari-hari berdasarkan dari kemampuan yang kita miliki tanpa mempelajari terlebih dahulu. Keputusan diambil berdasarkan bentuk pilihan informasi yang ada dan sesuai dengan prioritas dan menggunakan proses kesukaan hati, yang pada akhirnya mendapatkan sebuah keputusan yang terbaik.

Indonesia akan melakukan Pesta Demokrasi dalam pemilihan Kepala Negara yaitu pemilihan Presiden dan Wakil Presiden secara langsung pada bulan April Tahun 2019. Dalam pemilihan Presiden dan Wakil Presiden Tahun 2019 ini ada dua alternatif Pasangan Calon (Paslon) Presiden dan Wakil Presiden yang ikut dalam Pesta Demokrasi tersebut, pasangan calon itu adalah Joko DOI: https://doi.org/10.30743/infotekjar.v3i2.1067

\begin{abstract}
A B $\mathbf{S} \mathbf{T} \mathbf{R}$ A $\mathbf{C}$ T
Election is an activity carried out by a community in selecting people who occupy certain political positions. Before making an election, socialization is carried out by people who will take up the political position. The tendency of the community when making elections in determining which candidates will be chosen, the community does not assess the overall potential possessed by each candidate, even the community only sees one of the potential possessed by the candidate, from the results of a temporary survey conducted by asking questions directly to 10 respondents in the field, 4 respondents determined their choice based on popularity only, 3 respondents looked in terms of organization and the way of campaign of each candidate, the rest there were those who made choices when they were selected. so we need a system that supports making a decision, the application of the Analitycal Hierarchy Proccess (AHP) method as an reinforcer and supports in making a decision based on characteristics that are considered to represent the whole. The data used in the form of quantitative data from weighting is done through distributing questionnaires to the sample. From the analysis process carried out to help make a decision in the 2019 Presidential election, it can be concluded that the most important priorities to the last are Competence (46.82\%), Aspectivity (25.50\%), Integrity (13.54\%), Electability (7.19\%), Campaign $(4.51 \%)$ Coalition Party $(2.42 \%)$. Whereas for alternative use data is obtained, namely the highest value weight, namely candidate pairs with Number. Sort 01 (Joko Widodo and Ma'ruf Amin) with a score of 85.9\%. while the candidate pairs with serial number 02, Prabowo Subianto and Sandiaga Uno, scored $14.1 \%$.
\end{abstract}

Widodo yang didampingi oleh Ma'ruf Amin sebagai pasangan calon untuk nomor urut 01 dan Prabowo Subianto yang didampingi oleh Sandiaga Uno untuk nomor urut 02.

Dalam melakukan pemilihan, masyarakat tentunya harus cermat dalam menentukan Capres dan Cawapres pilihan yang mampu memimpin Indonesia agar Indonesia menjadi lebih baik lagi. Tentunya dalam menentukan pilihan masyarakat harus melihat kriteria-kriteria yang dimiliki oleh setiap kandidat-kandidat tersebut. Hal ini bisa dilihat pada waktu sosialisasi atau kampanye setiap kandidat, padangan kandidat tersebut akan menjelaskan tentang apa yang akan dilakukannya ketika terpilih menjadi Presiden dan Wakil Presiden 2019 nantinya.

Dalam melakukan kampanye, setiap kandidat memiliki strategi tersendiri untuk meyakinkan rakyat agar memilih kandidat

Attribution-NonCommercial 4.0 International. Some rights reserved 
tersebut pada saat pemilihan. Startegi yang digunakan untuk memenagkan kampanye tersebut diantaranya adalah menggunakan bahasa istilah saat berkampanye, hal ini tentunya akan memberikan efek bagi masyarakat dalam menentukan pilihan, lebih-lebih masyarakat awam yang tidak memahami secara menyelutuh apa arti dari penggunaan istilah tersebut. Pentingnya penggunaan istilah-istilah dalam berpolitik juga sangat diperlukan bagi kandidat, hal ini akan memperlihatkan bahwa kandidat tersebut memiliki wawasan dan pengetahuan yang luas, bahkan dengan penggunaan bahasa istilah tersebut mampu meningkatkan elektabilitas dari masing-masing kandidat. Selain menggunakan bahasa atau istilah dalam kampanye, banyak kriteria lain lain yang akan mempengaruhi masyarakat dalam menentukan kandidat yang sesuai dengan harapan rakyat untuk memimpin bangsa ini. Salah satu contoh kriteria yang dapat mempengaruhi adalah Partai Koalisi, Kampanye, Integritas, Elektabilitas, Akseptabilitas, Kompetensi.

Kecendrungan masyarakat pada saat melakukan pemilihan dalam menentukan pasangan mana yang akan dipilih, masyarakat tidak menilai secara keseluruhan potensi yang dimiliki oleh setiap kandidat, bahkan masyarakat hanya melihat salah satu potensi yang dimiliki oleh kandidat tersebut, misalnya elektabilitas yang tingi dari dua kandidat tersebut dapat dianggap telah memenuhi semua potensi yang dimiliki oleh kandidat yang dipilihnya. Dari hasil survey yang dilakukan dengan mengajukan pertanyaan langsung kepada 10 responden di lapangan, 4 orang responden menentukan pilihan mereka berdasarkan dari segi popularitas saja, 3 orang responden melihat dari segi organisasi dan cara kampanye dari masing-masing kandidat, selebihnya ada yang menentukan pilihan saat pemilhan saja. Hal ini membuat peneliti ingin memberikan gambaran secara jelas kepada masyarakat yang memilih agar menilai semua aspek yang dimiliki oleh setiap kandidat. Dengan memanfaatkan sebuah metode dalam membuat sebuah Sistem Pendukung Keputusan (SPK), hendaknya dapat membantu masyarakat dalam menentukan kandidat mana yang mampu menjadi Presiden dan Wakil Presiden terpilih. Akan tetapi dengan adanya SPK ini, bukan berati masyarakat harus mempercayai secara keseluruhan hasil yang diberikan, hal ini tergantung dengan hati nurani masyarakat itu sendiri dalam menentukan pilihannya.

\section{METHOD}

Dalam pembuatan sistem pendukung keputusan ini, metode yang diterapkan dalam penelitian ini adalah SDLC (System Development Life Cycle), dengan model yang digunakan adalah model Waterfall, dimana dalam penerapan metode ini dilakukan beberapa tahapan-tahapan agar penelitian ini terarah. Adapun tahapan-tahapan yang digunakan adalah:

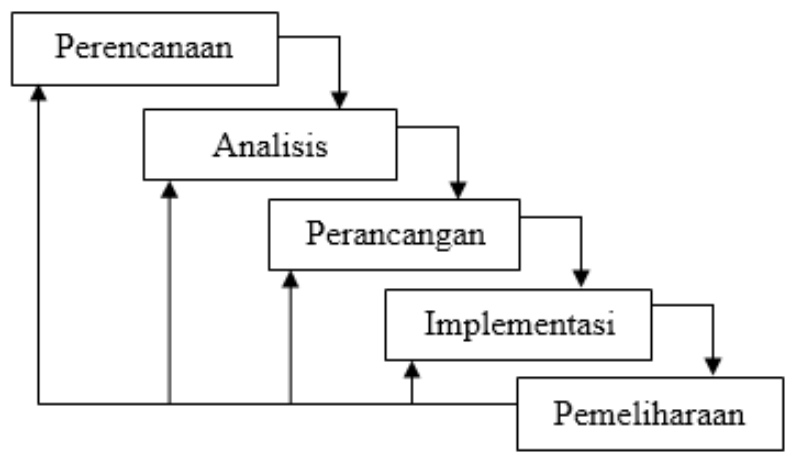

Gambar 1. Metode Waterfall

Tahap Perencanaan

Merupakan tahap menentukan tujuan dan target yang hendak dicapai dengan mengamati kejadian di lapangan.

Tahap Analisis

Penentuan kriteria yang digunakan dan alternatif yang dapat mewakili dari tujuan yang telah ditentukan, metode dalam mengumpulkan data mentah serta cara menganalisis data yang akan digunakan.

Tahap Perancangan

Tahap perancangan ini digunakan untuk merekapitulasi data kedalam bentuk data yang mudah dipahami, bentuk yang digunakan adalah bentuk tabel.

Tahap Implementasi

Melakukan analisi data dan dilakukan pengolahan data menggunakan software super decision serta pembuatan kesimpulan dari hasil yang diperoleh.

Tahap Pemeliharaan

Tahapan ini dilakukan jika hasil yang didapatkan pada proses sebelumnya menemukan permasalahan atau hasil tidak sesuai dengan yan diinginkan, maka dilakukan pengulangan pada tahap yang sesuai dengan hasil analisis.

\section{Pengumpulan Data}

Sebelum dilakukan proses analisis data, maka dilakukan pengumpulan data yang digunakan agar hasil yang akan diperoleh dalam penelitian ini sesuai dengan keadaan data di lapangan, teknik pengumpulannya adalah:

Populasi dan sampel

Dalam menentukan populasi dan sampel, teknik clustered (area) random sampling efektitif dalam penarikan sample, pada teknik ini sampel yang telah ditentukan berdasarkan area dan dipilih secara acak akan dilakukan pengumpulan data.

\section{Kuesioner}

Agar penelitian berjalan sesuai dengan target capaian, pengumpulan data dilakukan dengan memberikan kuesioner yang berisi daftar tanya tentang kriteria dan alternatif yang digunakan, sehingga responden bisa dengan mudah dalam dalam melakukan pengisian data. Dalam penelitian (Sujaini, Pratiwi, \& Sofhian, 2016) sebuah daftar yang berisikan sekumpulan perntanyaan yang harus dijawab oleh responden. 


\section{Rekapitulasi}

Setelah pengisian kuesioner, data yang diperoleh akan dilakukan rekapitulasi pada microsoft excel, rekapitulasi dilakukan dengan cara membuat tabel berdasarkan bobot nilai yang ditemukan berdasarkan data kuesioner.

\section{Pengolahan Data}

Data yang telah direkap pada proses sebelumnya, kemudian dilakukan pengolahan dengan software super decision. Pada aplikasi super decision tersebut, data diinput sesuai dengan kreteria dan alternatif dari masing-masing kandidat.

\section{Metode Analisa}

Untuk menggambarkan suatu uraian kegiatan dari sistem informasi ini akan didefinisikan setiap proses yang terjadi seperti mengevaluasi permasalahan dan penggunaan informasi yang dibutuhkan untuk memperbaiki sistem. Sehingga memerluka langkah pada analisa sistem antara lain:

\section{Activity Diagram}

Activity diagram digunakan untuk membuat sebuah langkah kerja pada sebuah proses dan mengurutkan kegiatan yang terjadi pada suatu proses.

\section{Use Case Diagram}

Use case diagram digunakan untuk menjelaskan cara pandang user yang berada di luar sistem serta manfaat sistem yang telah dibuat.

\section{Objek Penelitian}

Pelaksanaan penelitian ini dilakukan pada masyarakat kota Batam dengan menggunakan sampel. Jika dilihat menggunakan pencitraan lokasi menggunakan peta, maka lokasi dapat digambarkan seperti berikut:

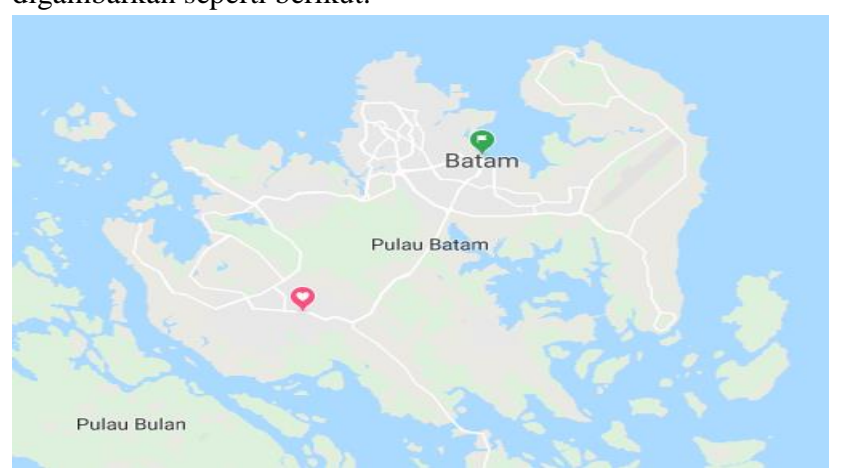

Sumber: https://www.google.com/maps/place/Batam

Gambar 2. Lokasi Penelitian

\section{Analisis Masalah dan Solusi}

Dalam pembuatan sistem pendukung keputusan yang dilakukan di Kota Batam ini menggunakan model Waterfall, dimana pada model ini tahapan yang digunakan berbentuk jenjang sehingga permasalahan dapat diselesaikan secara terarah. Berdasarkan hasil temuan dilapangan, kecendrungan masyarakat hanya menentukan pilihan berdasar dari satu atau dua potensi yang dimiliki oleh pasangan kandidat, dan tidak menilai secara keseluruhan potensi. Hal ini nantinya akan berdampak terhadap pasangan kandidat yang terpilih tidak sesuai dengan harapan yang kita inginkan, sehingga dibutuhkan sebuah sistem yang mampu mendukung dalam membuat sebuah keputusan, dimana sistem tersebut mampu menilai semua potensi yang dimiliki oleh setiap pasangan calon.

\section{Metode Analisis data}

Setelah tahapan pengumpulan data dilakukan, kemudian dilakukan proses rekapitulasi data agar data yang terkumpul mudah untuk dipahami dan dimengerti sebelum analisis data dilakukan. Penggunaan metode analisis melalui memanfaatkan software super decision. Pada pengaplikasiannya, data yang telah dilakukan rekapitulasi selanjutanya diberikan bobot nilai sesuai dari data kuesioner, kemudian dilakukan penginputan data pada software serta menarik sebuah kesimpulan sebagai hasil akhir sebuah proses analisa.

\section{RESULTS AND DISCUSSION}

Dalam menentukan pasangan calon mana yang akan dipilih menjadi Presiden 2019 pada pemilihan umum nantinya diperlukan beberapa kriteria yang digunakan untuk mendapatkan hasil yang sesuai dengan kondisi saat ini, dimana kriteria yang digunakan dapat dilihat pada tabel berikut:

Tabel 1. Penggunaan Kriteria

\begin{tabular}{ccc}
\hline No & Kriteria & Keterangan \\
\hline 1 & PK & Partai Koalisi \\
2 & KP & Kampanye \\
3 & IG & Integritas \\
4 & EB & Elektabilitas \\
5 & AB & Aspekbilitas \\
6 & KT & Kompetensi \\
\hline
\end{tabular}

Setelah penetapan pilihan Kriteria yang digunakan, setiap kriteria tersebut akan diberikan pembobotan nilai untuk setiap kriteria. Langkah selanjutnya dilakukan proses analisa berdasarkan perolehan data dilapangan, hasil pencapaian yang dari proses analisis tersebut adalah mendapatkan nilai dari alternatif dalam menentukan pilihan yang hendak dipilih. Selain penentuan kriteria yang digunakan, dalam menentukan hasil akhir atau tujuan yang hendak dicapai juga diperlukan alternatif agar penelitian sesuai dengan yang diinginkan, adapun alternatif yang digunakan dalam mendukung penelitian ini dapat dilihat pada tabel berikut:

Tabel 2. Penggunaan Alternatif

\begin{tabular}{lll} 
No & Alternatif & Keterangan \\
\hline 1 & No. Urut 01 & $\begin{array}{l}\text { Pasangan Calon Presiden Joko Widodo } \\
\text { dan Ma'ruf Amin } \\
\text { Pasangan Calon Presiden Prabowo } \\
\text { Subianto dan Sandiaga Uno }\end{array}$ \\
\hline
\end{tabular}

Untuk pembobotan digunakan nilai tingkat kepentingan untuk melakukan penilaian terhadap alternatif, yaitu:

Tabel 3. Bobot Nilai Tingkat Kepentingan

\begin{tabular}{cc}
\hline $\begin{array}{c}\text { Tingkat } \\
\text { Kepentingan }\end{array}$ & Bobot \\
\hline 1 & Sangat Tinggi \\
2 & Tinggi \\
3 & Sedang \\
4 & Rendah
\end{tabular}


Sangat Rendah

Sementara dalam menentukan tujuan atau hasil akhir yang ingin dicapai, maka diperlukan urutan hirarki berdasarkan kriteria dan alternatif yang digunakan, tujuannya adalah agar penelitian bisa berjalan sesuai dengan target berdasarkan dari urutan hirarkinya, untuk lebih jelas dapat dilihat pada gambar berikut:

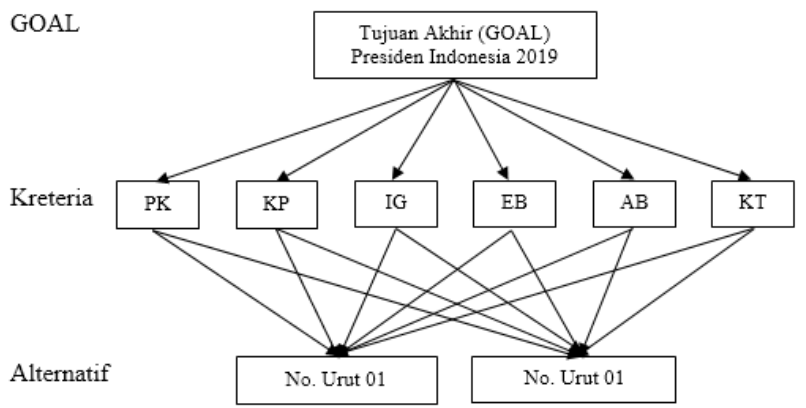

Gambar 3. Struktur Hirarki Presiden 2019

\section{Pembahasan}

Dalam penerapan metode AHP dilakukan dengan cara membuat perbandingan berpasangan, dimana untuk mendapatkan keputusan berdasarkan hirarki yang telah ditentukan. Hasil dari pengolahan perbandingan berpasangan sebelumnya dilakukan penetapan nilai eigen faktor dan evaluasinya. Hasil dari evaluasi tersebut dapat kita urutkan lagi menjadi bentuk perengkingan untuk mendapat hasil yang terbaik.

\section{Penyusunan Hirarki}

Struktur hirarki yang akan di bangun untuk menentukan Presiden Indonesia 2019 yang akan dijadikan sebagai tujuan dari analisis ini. Mentukan tujuan yang merupakan sasaran sistem pada level teratas yaitu Presiden Indonesia 2019. Level berikutnya terdiri dari kriteria-kriteria untuk menilai atau pertimbangan alternatif yang ada pada level dibawahnya yaitu Aspekbilitas (AB), Elektabilitas (EB), Integritas (IG), Kampanye (KP), Kompetensi (KT) dan Partai Koalisi (PK). Setiap kriteria dapat memiliki nilai intensitas masing-masing, dan nilai alternatif terdiri dari Pasangan Calon dengan nomor urut 01 yaitu Joko Widodo dan Ma'ruf Amin dan Pasangan Calon dengan nomor urut 02 yaitu Prabowo Subianto dan Sandiaga Uno.

\section{Menentukan Prioritas Element}

Matrik Berpasangan Kriteria

Hirarki pada gambar diatas tersebut menampilkan bahawa faktor yang dinilai serta berbagai alternatif yang dimiliki. Untuk menentukan nilai faktor tersebut maka perlu dibuat urutan prioritas serta perbandingan untuk setiap kriteria. Dibawah ini ditampilkan tabel kriteria yang akan dibuat berdasarkan gambar hirarki yang telah ada dan ditentukan kode dari kriteria tersebut agar mempermudah dalam proses analisis pada tahap berikutnya.

Tabel 4. Skala Perbandingan antar kriteria

$\begin{array}{lllllll} & \mathrm{AB} & \mathrm{EB} & \mathrm{IG} & \mathrm{KP} & \mathrm{KT} & \mathrm{PK} \\ \mathrm{AB} & 1,00 & & & & & \\ \mathrm{~EB} & & 1,00 & & & & \\ \mathrm{IG} & & & 1,00 & & & \\ \mathrm{KP} & & & & 1,00 & & \\ \mathrm{KT} & & & & & 1,00 & \\ \mathrm{PK} & & & & & & 1,00\end{array}$

Skala perbandingan kriteria pada tabel diatas kemudian dijadikan sebuah matriks berpasangan untuk dijadikan dasar perhitungan selanjutnya. Pengisia tabel matrik skala perbandingan.

Tabel 5. Matrik Berpasangan

$\begin{array}{lllllll} & \text { AB } & \text { EB } & \text { IG } & \text { KP } & \text { KT } & \text { PK } \\ \text { AB } & 1,00 & 6,00 & 6,00 & 6,00 & 0,17 & 6,00 \\ \text { EB } & 0,17 & 1,00 & 0,17 & 5,00 & 0,17 & 5,00 \\ \text { IG } & 0,17 & 6,00 & 1,00 & 5,00 & 0,17 & 6,00 \\ \text { KP } & 0,17 & 0,20 & 0,20 & 1,00 & 0,17 & 6,00 \\ \text { KT } & 6,00 & 6,00 & 6,00 & 6,00 & 1,00 & 6,00 \\ \text { PK } & 0,17 & 0,20 & 0,17 & 0,17 & 0,17 & 1,00\end{array}$

Setelah pemberian bobot nilai berdasarkan data yang ditemukan, selanjutnya dilakukan penghitungan untuk mencari eigen vaktor, untuk mendapatkan nilai eigen vektor menjadi valid maka perhitungan matik dilakukan sampai proses iterasi kedua, berikut perhitungan nilai eigen vektor 1 dan nilai eigen vektor 2 .

Tabel 6. Nilai Eigen Vektor 1

\begin{tabular}{lllllll}
\hline & AB & EB & IG & KP & KT & PK \\
\hline AB & 6,10 & 51,42 & 16,26 & 74,04 & 4,42 & 115,02 \\
EB & 3,09 & 6,06 & 4,23 & 13,74 & 2,10 & 43,06 \\
IG & 4,25 & 16,24 & 6,08 & 43,06 & 3,26 & 74,04 \\
KP & 2,45 & 4,84 & 3,49 & 6,06 & 1,46 & 16,24 \\
KT & 16,08 & 86,40 & 51,24 & 109,02 & 6,10 & 150,00 \\
PK & 1,45 & 3,49 & 2,45 & 4,23 & 0,46 & 6,08 \\
\hline
\end{tabular}

Dari proses perkalian matrik pada nilai eigen vaktor 1, dilakukan perhitungan hasil untuk memperoleh data normaslisasi, berikut hasil dari nilai eigen vaktor 1 :

Tabel 7. Hasil Normalisasi Nilai Eigen Vektor Pertama

\begin{tabular}{c}
\hline Nilai Eigen Vektor 1 \\
\hline 0,279 \\
0,075 \\
0,153 \\
0,036 \\
0,437 \\
0,019
\end{tabular}

Setelah perhitungan nilai eigen 1 selesai dihitung, maka dialnjutkan dengan menghitung nilai eigen vektor 2. Berikut bentuk perhitungan nilai eigen vaktor 2 :

Tabel 8. Nilai Eigen Vektor 2

$\begin{array}{ccccccc} & \text { AB } & \text { EB } & \text { IG } & \text { KP } & \text { KT } & \text { PK } \\ \text { AB } & 684,46 & 2031,45 & 1182,30 & 3275,40 & 375,64 & 6684,39 \\ \text { EB } & 185,42 & 662,45 & 362,49 & 988,22 & 92,80 & 1729,03 \\ \text { IG } & 367,23 & 1164,36 & 673,45 & 1729,03 & 189,39 & 3276,59 \\ \text { KP } & 106,57 & 423,90 & 217,10 & 662,45 & 57,56 & 1164,36 \\ \text { KT } & 1165,48 & 3761,35 & 1999,15 & 6544,28 & 684,46 & 12961,20 \\ \text { PK } & 56,64 & 217,10 & 106,54 & 362,49 & 33,50 & 673,45\end{array}$

Adapun hasil normalisasi dari nilai eigen vektor pertama adalah:

Tabel 9. Hasil Normalisasi Nilai Eigen Vektor Pertama NILAI Eigen Vektor 2

0,250

0,071

0,130

0,046 
0,477

0,026

Setelah hasil yang ditemukan pada perkalian matik eigen vektor 1 dan eigen vaktor 2, maka dihitung selisih nilai dari kedua tersebut sehingga menjadi hasil akhir dari proses nilai normalisasi. Semakin kecil selisih nilai diperoleh, maka hasil analisa tersebut dapat dikatakan valid.

Tabel 10. Selisih Hasil Normalisasi Nilai Eigen Vektor

\begin{tabular}{ccc}
\hline Nilai EV1 & Nilai EV2 & Selisih \\
\hline 0,279 & 0,250 & 0,029 \\
0,075 & 0,071 & 0,005 \\
0,153 & 0,130 & 0,023 \\
0,036 & 0,046 & $-0,010$ \\
0,437 & 0,477 & $-0,040$ \\
0,019 & 0,026 & $-0,007$ \\
\hline
\end{tabular}

Setelah dilakukan perhitungan selisih dari kedua nilai eigen vektor dan dinyatakan valid maka akan menunjukkan bahwa nilai eigen vektor 1 tersebut sudah valid, sehingga untuk mencari nilai bobot setiap kriteria bisa dilakukan dan dapat memberikan gambaran prioritas kriteria dalam bentuk perengkingan.

Tabel 11. Perengkingan Nilai Hasil Normalisasi Nilai Eigen

\begin{tabular}{lcccc}
\multicolumn{1}{c}{ Kriteria } & Kode & $\begin{array}{c}\text { Eigen } \\
\text { Vektor }\end{array}$ & $\begin{array}{c}\text { Bobot } \\
(\%)\end{array}$ & Prioritas \\
Aspekbilitas & AB & 0,279 & 27,90 & 2 \\
Eletabilitas & EB & 0,075 & 7,54 & 4 \\
Integritas & IG & 0,153 & 15,34 & 3 \\
Kampanye & KP & 0,036 & 3,61 & 5 \\
Kompetensi & KT & 0,437 & 43,72 & 1 \\
Partai Koalisi & PK & 0,019 & 1,90 & 6
\end{tabular}

Dilihat dari hasil peranghkingan di atas, dapat disimpulkan bahwa nilai prioritas yang paling utama ditunjukkan pada Kompetensi (KT) sebesar 43,72\%, prioritas kedua yaitu Aspekbilitas (AB) sebesar 27,90, prioritas ketiga yaitu Integritas (IG) sebesar $15,34 \%$, prioritas keempat yaitu Elektabilitas (EB) Sebesar 7,45\%, prioritas kelima yaitu Kampanye (KP) Sebesar 3,61\% dan prioritas keenam yaitu Partai Koalisi (PK) sebesar 1,90\%.

Pada metode AHP, perlu dilakukan perhitungan nilai konsistensi rasio untuk hasil eigen vektor setiap nilai kriteria. Karena semakin besar nilai rasio konsistensi, maka semakin tidak konsisten pula hasil penilaiannya. Rumus untuk menghitung rasio konsistensi yaitu :

$$
\mathrm{CI}=\frac{\lambda \text { maks }-\mathrm{n}}{\mathrm{n}-1} \quad \text { dan } \quad \mathrm{CR}=\frac{\mathrm{CI}}{\mathrm{RI}}
$$

Rumus 1. Rasio Konsistensi

Mencari nilai $\lambda$ maks yaitu dengan cara menjumlahkan nilai setiap kolom sehingga didapatkan nilai total kolom kriteria. Kemudian lakukan perkalian terhadap nilai hasil normalisasi eigen vektor 1, dan lakukan perkalian seterusnya sampai didapatkan nilai pada setiap barisnya. Kemudian jumlahkan semua nilai hasil perkalian untuk mendapatkan nilai $\lambda$ maks.

Tabel 12. Mencari Nilai CI dan $\lambda$ maks

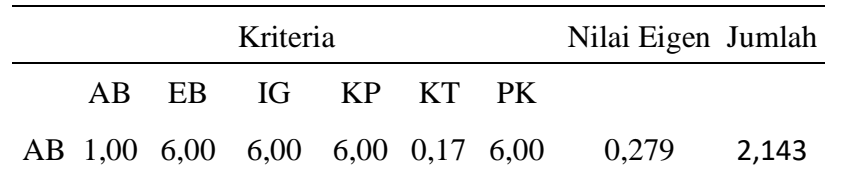

DOI: https://doi.org/10.30743/infotekjar.v3i2.1067

$\begin{array}{lllllllll}\text { EB } & 0,17 & 1,00 & 0,17 & 5,00 & 0,17 & 5,00 & 0,075 & 1,455 \\ \text { IG } & 0,17 & 6,00 & 1,00 & 5,00 & 0,17 & 6,00 & 0,153 & 2,072 \\ \text { KP } & 0,17 & 0,20 & 0,20 & 1,00 & 0,17 & 6,00 & 0,036 & 0,834 \\ \text { KT } & 6,00 & 6,00 & 6,00 & 6,00 & 1,00 & 6,00 & 0,437 & 0,808 \\ \text { PK } & 0,17 & 0,20 & 0,17 & 0,17 & 0,17 & 1,00 & 0,019 & 0,570\end{array}$

$\begin{array}{llllll}7,68 & 19,40 & 13,54 & 23,17 & 1,85 & 30,00\end{array}$

Tahapan selanjutnya adalah mencari nilai CI dan $\lambda$ maks dengan cara :

$\lambda$ maks $=(7,68 \times 0,279)+(19,40 \times 0,075)+(13,54 \times 0,153)+$ $(23,17 \times 0,036)+(1,85 \times 0,437)$

$(30,00 \times 0,019)$

$\lambda$ maks $=7,882$

Karena matriks berordo 6 (terdiri dari 6 kriteria), berdasarkan dari tabel Saaty, maka nilai indeks konsistensi yang diperoleh adalah:

$$
\begin{aligned}
\text { CI } & =\frac{\lambda \text { maks }-\mathrm{n}}{n-1} \\
& =\frac{7,882-6}{6-1} \\
\text { CI } & =0,376
\end{aligned}
$$

Setelah mencari nilai CI, selanjutnya menentukan Cosistency Rasio dengan cara membagi hasil indeks konsistensi dengan nilai indesks random. Untuk $n=6$, maka $R I=1,12$ (tabel Saaty), maka:

$$
\begin{aligned}
\mathrm{CR} & =\frac{\mathrm{CI}}{\mathrm{RI}} \\
& =\frac{0,376}{1,12} \\
\mathrm{CR} & =0,336
\end{aligned}
$$

Karena nilai CR yang diperoleh $<0,100$ maka nilai dari rasio konsistensi tersebut dapat dikatakan bahwa hasil penelitian konsisten.

\section{Matrik Berpasangan Alternatif}

Dalam melakukan perhitungan pada matrik berpasangan alternatif, perhitungan dilakukan dengan cara yang sama dalam melakukan perhitungan pada matrik berpasangan kriteria. Sebagai contoh untuk kriteria Aspekbilitas (AB) dibandingkan dengan alternatif No. Urut 01 dan No. Urut 02. Begitu juga untuk yang digunakan pada kriteria Aspekbilitas (AB), Elektabilitas (EB), Integritas (IG), Kampanye (KP), Kompetensi (KT) dan Partai Koalisi (PK) terhadap alternatif No. Urut 01 dan No. Urut 02 .

Matrik Perbandingan alternatif dengan kriteria Aspekbilitas (AB)

Untuk matrik perbadingannya dapat dilihat pada tabel berikut ini: Tabel 13. Matrik Kriteria Aspekbilitas (AB)

\begin{tabular}{lll}
\hline Aspekbilitas $(\mathrm{AB})$ & No. Urut 01 & No. Urut 02 \\
\hline No. Urut 01 & 1,00 & 6,00 \\
No. Urut 02 & 0,17 & 1,00 \\
\hline
\end{tabular}

Perhitungan Nilai Eigen 1

\begin{tabular}{cllll}
\hline AB & $\begin{array}{c}\text { No. } \\
\text { Urut 01 }\end{array}$ & $\begin{array}{c}\text { No. } \\
\text { Urut 02 }\end{array}$ & Jumlah & $\begin{array}{c}\text { Nilai } \\
\text { Eigen } \\
\text { Vektor 1 }\end{array}$ \\
\hline No. Urut 01 & 2,00 & 12,00 & 14,00 & 0,857 \\
No. Urut 02 & 0,33 & 2,00 & 2,33 & 0,143 \\
\hline
\end{tabular}


Perhitungan Nilai Eigen 2

\begin{tabular}{ccccc}
\hline AB & $\begin{array}{c}\text { No. } \\
\text { Urut 01 }\end{array}$ & $\begin{array}{c}\text { No. } \\
\text { Urut 02 }\end{array}$ & Jumlah & $\begin{array}{c}\text { Nilai } \\
\text { Eigen } \\
\text { Vektor 1 }\end{array}$ \\
\hline No. Urut 01 & 8,00 & 12,00 & 56,00 & 0,857 \\
No. Urut 02 & 1,33 & 8,00 & 9,33 & 0,143 \\
\hline
\end{tabular}

Perhitungan Normalisasi dengan cara mengurangi hasil Nilai Eigen 1 dengan Nilai Eigen 2.

\begin{tabular}{ccc}
\hline $\begin{array}{c}\text { Nilai Eigen } \\
\text { Vektor } 1\end{array}$ & $\begin{array}{c}\text { Nilai Eigen } \\
\text { Vektor 2 }\end{array}$ & $\begin{array}{c}\text { Hasil } \\
\text { Normalisasi }\end{array}$ \\
\hline 0,857 & 0,857 & 0,000 \\
0,143 & 0,143 & 0,000 \\
\hline
\end{tabular}

Karena selisih antara nilai eigen 1 dengan nilai eigen 2 menunjukkan tidak ada perbedaan, maka pencarian nilai eigen 3 tidak perlu dilakukan hal ini menyatakan bahwa hasil nomalisasi telah memnuhi syarat. Untuk hasil prioritas kriteria Aspekbilitas (AB) terhadap alternatif No. Urut 01 dan No. Urut 02 dapat dilihat pada tabel berikut:

Tabel 14. Prioritas kriteria Aspekbilitas (AB)

\begin{tabular}{ccccc}
\hline $\begin{array}{c}\text { Aspekbilitas } \\
(\mathrm{AB})\end{array}$ & No. & No. & Nilai & $\begin{array}{c}\text { Prioritas } \\
(\%)\end{array}$ \\
\hline No. Urut 01 & 1,00 & 6,00 & 0,857 & 85,7 \\
No. Urut 02 & 0,17 & 1,00 & 0,143 & 14,3 \\
\hline
\end{tabular}

Pada tabel diatas dapat dilihat bahwa untuk pasangan No. Urut 01 memiliki Aspekbilitas (AB) dengan nilai 87,5\%, sedangkan untuk pasangan No. Urut 02 dengan nilai $14,3 \%$.

Matrik Perbandingan alternatif dengan kriteria Elektabilitas (EB)

Untuk matrik perbadingannya dapat dilihat pada tabel berikut ini:

Tabel 15. Matrik kriteria Elektabilitas (EB)

\begin{tabular}{lll}
\hline Elektabilitas (EB) & No. Urut 01 & No. Urut 02 \\
\hline No. Urut 01 & 1,00 & 6,00 \\
No. Urut 02 & 0,17 & 1,00 \\
\hline
\end{tabular}

Perhitungan Nilai Eigen 1

\begin{tabular}{ccccc}
\hline EB & $\begin{array}{c}\text { No. } \\
\text { Urut 01 }\end{array}$ & $\begin{array}{c}\text { No. } \\
\text { Urut 02 }\end{array}$ & Jumlah & $\begin{array}{c}\text { Nilai } \\
\text { Eigen } \\
\text { Vektor 1 }\end{array}$ \\
\hline No. Urut 01 & 2,00 & 12,00 & 14,00 & 0,857 \\
No. Urut 02 & 0,33 & 2,00 & 2,33 & 0,143 \\
\hline
\end{tabular}

Perhitungan Nilai Eigen 2

\begin{tabular}{cllll}
\hline EB & $\begin{array}{c}\text { No. } \\
\text { Urut 01 }\end{array}$ & $\begin{array}{c}\text { No. } \\
\text { Urut 02 }\end{array}$ & Jumlah & $\begin{array}{c}\text { Nilai } \\
\text { Eigen } \\
\text { Vektor 1 }\end{array}$ \\
\hline No. Urut 01 & 8,00 & 48,00 & 56,00 & 0,857 \\
No. Urut 02 & 1,33 & 8,00 & 9,33 & 0,143 \\
\hline
\end{tabular}

Perhitungan Normalisasi dengan cara mengurangi hasil Nilai Eigen 1 dengan Nilai Eigen 2.

\begin{tabular}{ccc}
\hline $\begin{array}{c}\text { Nilai Eigen } \\
\text { Vektor } 1\end{array}$ & $\begin{array}{c}\text { Nilai Eigen } \\
\text { Vektor } 2\end{array}$ & $\begin{array}{c}\text { Hasil } \\
\text { Normalisasi }\end{array}$ \\
\hline 0,857 & 0,857 & 0,000 \\
0,143 & 0,143 & 0,000 \\
\hline
\end{tabular}

Karena selisih antara nilai eigen 1 dengan nilai eigen 2 menunjukkan tidak ada perbedaan, maka pencarian nilai eigen 3 tidak perlu dilakukan hal ini menyatakan bahwa hasil nomalisasi telah memnuhi syarat. Untuk hasil prioritas kriteria Elektabilitas (EB) terhadap alternatif No. Urut 01 dan No. Urut 02 dapat dilihat pada tabel berikut:

Tabel 16. Prioritas kriteria Elektabilitas (EB)

$\begin{array}{lllll}\text { Elektabilitas } & \text { No. } & \text { No. } & \text { Nilai } & \text { Prioritas } \\ \text { (EB) } & \text { Urut 01 } & \text { Urut 02 } & \text { Eigen } & (\%) \\ \text { No. Urut 01 } & 1,00 & 6,00 & 0,876 & 85,7 \\ \text { No. Urut } 02 & 0,17 & 1,00 & 0,124 & 14,3\end{array}$

Pada tabel diatas dapat dilihat bahwa untuk pasangan No. Urut 01 memiliki Elektabilitas (EB) dengan nilai 87,5\%, sedangkan untuk pasangan No. Urut 02 dengan nilai $14,3 \%$.

\section{Matrik Perbandingan alternatif dengan kriteria Integritas (IG)}

Untuk matrik perbadingannya dapat dilihat pada tabel berikut ini:

Tabel 17. Matrik Kriteria Integritas (IG)

$\begin{array}{lll}\text { Aspekbilitas (AB) } & \text { No. Urut 01 } & \text { No. Urut } 02 \\ \text { No. Urut 01 } & 1,00 & 7,00 \\ \text { No. Urut } 02 & 0,14 & 1,00\end{array}$

Perhitungan Nilai Eigen 1

\begin{tabular}{cllll}
\hline IG & $\begin{array}{c}\text { No. } \\
\text { Urut 01 }\end{array}$ & $\begin{array}{c}\text { No. } \\
\text { Urut 02 }\end{array}$ & Jumlah & $\begin{array}{c}\text { Nilai } \\
\text { Eigen } \\
\text { Vektor 1 }\end{array}$ \\
\hline No. Urut 01 & 1,98 & 14,00 & 15,98 & 0,876 \\
No. Urut 02 & 0,28 & 1,98 & 2,26 & 0,124 \\
\hline
\end{tabular}

Perhitungan Nilai Eigen 2

\begin{tabular}{ccclc}
\hline IG & $\begin{array}{c}\text { No. } \\
\text { Urut 01 }\end{array}$ & $\begin{array}{c}\text { No. } \\
\text { Urut 02 }\end{array}$ & Jumlah & $\begin{array}{c}\text { Nilai } \\
\text { Eigen } \\
\text { Vektor 1 }\end{array}$ \\
\hline No. Urut 01 & 7,84 & 55,44 & 63,28 & 0,876 \\
No. Urut 02 & 1,11 & 7,84 & 8,95 & 0,124 \\
\hline
\end{tabular}

Perhitungan Normalisasi dengan cara mengurangi hasil Nilai Eigen 1 dengan Nilai Eigen 2.

\begin{tabular}{ccc}
\hline $\begin{array}{c}\text { Nilai Eigen } \\
\text { Vektor } 1\end{array}$ & $\begin{array}{c}\text { Nilai Eigen } \\
\text { Vektor } 2\end{array}$ & $\begin{array}{c}\text { Hasil } \\
\text { Normalisasi }\end{array}$ \\
\hline 0,876 & 0,876 & 0,000 \\
0,124 & 0,124 & 0,000 \\
\hline
\end{tabular}

Karena selisih antara nilai eigen 1 dengan nilai eigen 2 menunjukkan tidak ada perbedaan, maka pencarian nilai eigen 3 tidak perlu dilakukan hal ini menyatakan bahwa hasil nomalisasi telah memnuhi syarat. Untuk hasil prioritas kriteria Integritas (IG) terhadap alternatif No. Urut 01 dan No. Urut 02 dapat dilihat pada tabel berikut:

Tabel 18. Prioritas kriteria Integritas (IG) 


$\begin{array}{lllll}\text { Integritas } & \text { No. } & \text { No. } & \text { Nilai } & \begin{array}{l}\text { Prioritas } \\ \text { (IG) }\end{array} \\ \text { Urut 01 } & \text { Urut 02 } & \text { Eigen } & (\%) \\ \text { No. Urut 01 } & 1,00 & 7,00 & 0,876 & 87,6 \\ \text { No. Urut 02 } & 0,14 & 1,00 & 0,124 & 12,4\end{array}$

Pada tabel diatas dapat dilihat bahwa untuk pasangan No. Urut 01 memiliki Integritas (IG) dengan nilai 87,5\%, sedangkan untuk pasangan No. Urut 02 dengan nilai $12,4 \%$.

\section{Matrik Perbandingan alternatif dengan kriteria Kampanye (KP)}

Untuk matrik perbadingannya dapat dilihat pada tabel berikut ini:

Tabel 19. Matrik kriteria Kampanye (KP)

$\begin{array}{lll}\text { Kampanye (KP) } & \text { No. Urut } 01 & \text { No. Urut } 02 \\ \text { No. Urut } 01 & 1,00 & 6,00 \\ \text { No. Urut } 02 & 0,17 & 1,00\end{array}$

Perhitungan Nilai Eigen 1

\begin{tabular}{ccccc}
\hline KP & $\begin{array}{c}\text { No. } \\
\text { Urut 01 }\end{array}$ & $\begin{array}{c}\text { No. } \\
\text { Urut 02 }\end{array}$ & Jumlah & $\begin{array}{c}\text { Nilai } \\
\text { Eigen } \\
\text { Vektor 1 }\end{array}$ \\
\hline No. Urut 01 & 2,00 & 12,00 & 14,00 & 0,857 \\
No. Urut 02 & 0,33 & 2,00 & 2,33 & 0,143 \\
\hline
\end{tabular}

Perhitungan Nilai Eigen 2

\begin{tabular}{ccccc}
\hline KP & $\begin{array}{c}\text { No. } \\
\text { Urut 01 }\end{array}$ & $\begin{array}{c}\text { No. } \\
\text { Urut 02 }\end{array}$ & Jumlah & $\begin{array}{c}\text { Nilai } \\
\text { Eigen } \\
\text { Vektor 1 }\end{array}$ \\
\hline No. Urut 01 & 8,00 & 48,00 & 56,00 & 0,857 \\
No. Urut 02 & 1,33 & 8,00 & 9,33 & 0,143 \\
\hline
\end{tabular}

Perhitungan Normalisasi dengan cara mengurangi hasil Nilai Eigen 1 dengan Nilai Eigen 2.

\begin{tabular}{ccc}
\hline $\begin{array}{c}\text { Nilai Eigen } \\
\text { Vektor } 1\end{array}$ & $\begin{array}{c}\text { Nilai Eigen } \\
\text { Vektor 2 }\end{array}$ & $\begin{array}{c}\text { Hasil } \\
\text { Normalisasi }\end{array}$ \\
\hline 0,857 & 0,857 & 0,000 \\
0,143 & 0,143 & 0,000 \\
\hline
\end{tabular}

Karena selisih antara nilai eigen 1 dengan nilai eigen 2 menunjukkan tidak ada perbedaan, maka pencarian nilai eigen 3 tidak perlu dilakukan hal ini menyatakan bahwa hasil nomalisasi telah memnuhi syarat. Untuk hasil prioritas kriteria Kampanye (KP) terhadap alternatif No. Urut 01 dan No. Urut 02 dapat dilihat pada tabel berikut:

Tabel 20. Prioritas kriteria Kampanye (KP)

\begin{tabular}{lllll}
\hline $\begin{array}{l}\text { Kampanye } \\
\text { (KP) }\end{array}$ & $\begin{array}{l}\text { No. } \\
\text { Urut 01 }\end{array}$ & $\begin{array}{l}\text { No. } \\
\text { Urut 02 }\end{array}$ & $\begin{array}{l}\text { Nilai } \\
\text { Eigen }\end{array}$ & $\begin{array}{l}\text { Prioritas } \\
(\%)\end{array}$ \\
\hline No. Urut 01 & 1,00 & 6,00 & 0,857 & 85,7 \\
No. Urut 02 & 0,17 & 1,00 & 0,143 & 14,3 \\
\hline
\end{tabular}

Pada tabel diatas dapat dilihat bahwa untuk pasangan No. Urut 01 memiliki Kampanye (KP) dengan nilai $87,5 \%$, sedangkan untuk pasangan No. Urut 02 dengan nilai $14,3 \%$.

\section{Matrik Perbandingan alternatif dengan kriteria Partai} Koalisi (PK)

Untuk matrik perbadingannya dapat dilihat pada tabel berikut ini:
Tabel 21. Matrik Kriteria Partai Koalisi (PK)

$\begin{array}{lll}\text { Partai Koalisi (PK) } & \text { No. Urut 01 } & \text { No. Urut } 02 \\ \text { No. Urut } 01 & 1,00 & 6,00 \\ \text { No. Urut } 02 & 0,17 & 1,00\end{array}$

Perhitungan Nilai Eigen 1

\begin{tabular}{ccccc}
\hline PK & $\begin{array}{c}\text { No. } \\
\text { Urut 01 }\end{array}$ & $\begin{array}{c}\text { No. } \\
\text { Urut 02 }\end{array}$ & Jumlah & $\begin{array}{c}\text { Nilai } \\
\text { Eigen } \\
\text { Vektor 1 }\end{array}$ \\
\hline No. Urut 01 & 2,00 & 12,00 & 14,00 & 0,857 \\
No. Urut 02 & 0,33 & 2,00 & 2,33 & 0,143 \\
\hline
\end{tabular}

Perhitungan Nilai Eigen 2

\begin{tabular}{ccccc}
\hline PK & $\begin{array}{c}\text { No. } \\
\text { Urut 01 }\end{array}$ & $\begin{array}{c}\text { No. } \\
\text { Urut 02 }\end{array}$ & Jumlah & $\begin{array}{c}\text { Nilai } \\
\text { Eigen } \\
\text { Vektor 1 }\end{array}$ \\
\hline No. Urut 01 & 8,00 & 48,00 & 56,00 & 0,857 \\
No. Urut 02 & 1,33 & 8,00 & 9,33 & 0,143 \\
\hline
\end{tabular}

Perhitungan Normalisasi dengan cara mengurangi hasil Nilai Eigen 1 dengan Nilai Eigen 2.

\begin{tabular}{ccc}
\hline $\begin{array}{c}\text { Nilai Eigen } \\
\text { Vektor } 1\end{array}$ & $\begin{array}{c}\text { Nilai Eigen } \\
\text { Vektor 2 }\end{array}$ & $\begin{array}{c}\text { Hasil } \\
\text { Normalisasi }\end{array}$ \\
\hline 0,857 & 0,857 & 0,000 \\
0,143 & 0,143 & 0,000 \\
\hline
\end{tabular}

Karena selisih antara nilai eigen 1 dengan nilai eigen 2 menunjukkan tidak ada perbedaan, maka pencarian nilai eigen 3 tidak perlu dilakukan hal ini menyatakan bahwa hasil nomalisasi telah memnuhi syarat. Untuk hasil prioritas kriteria Partai Koalisi (PK) terhadap alternatif No. Urut 01 dan No. Urut 02 dapat dilihat pada tabel berikut:

Tabel 22. Prioritas kriteria Partai Koalisi (PK)

\begin{tabular}{|c|c|c|c|c|}
\hline $\begin{array}{l}\text { Kampanye } \\
\text { (KP) }\end{array}$ & $\begin{array}{l}\text { No. } \\
\text { Urut } 01\end{array}$ & $\begin{array}{l}\text { No. } \\
\text { Urut } 02\end{array}$ & $\begin{array}{l}\text { Nilai } \\
\text { Eigen }\end{array}$ & $\begin{array}{l}\text { Prioritas } \\
(\%)\end{array}$ \\
\hline No. Urut 01 & 1,00 & 6,00 & 0,857 & 85,7 \\
\hline No. Urut 02 & 0,17 & 1,00 & 0,143 & 14,3 \\
\hline
\end{tabular}

Pada tabel diatas dapat dilihat bahwa untuk pasangan No. Urut 01 memiliki Partai Koalisi (PK) dengan nilai $87,5 \%$, sedangkan untuk pasangan No. Urut 02 dengan nilai $14,3 \%$.

\section{Matrik Perbandingan alternatif dengan kriteria Kompetensi} (KT)

Untuk matrik perbadingannya dapat dilihat pada tabel berikut ini: Tabel 23. Matrik Kriteria Kompetensi (KT)

$\begin{array}{lcc}\text { Kompetensi (KT) } & \text { No. Urut 01 } & \text { No. Urut 02 } \\ \text { No. Urut 01 } 01,00 & 7,00 \\ \text { No. Urut 02 } & 1,00,14 & 1,00\end{array}$

Perhitungan Nilai Eigen 1

\begin{tabular}{ccccc}
\hline KT & $\begin{array}{c}\text { No. } \\
\text { Urut 01 }\end{array}$ & $\begin{array}{c}\text { No. } \\
\text { Urut 02 }\end{array}$ & Jumlah & $\begin{array}{c}\text { Nilai } \\
\text { Eigen } \\
\text { Vektor 1 }\end{array}$ \\
\hline No. Urut 01 & 1,98 & 14,00 & 15,98 & 0,876 \\
No. Urut 02 & 0,28 & 1,98 & 2,26 & 0,124 \\
\hline
\end{tabular}

Perhitungan Nilai Eigen 2 


\begin{tabular}{ccccc}
\hline KT & $\begin{array}{c}\text { No. } \\
\text { Urut 01 }\end{array}$ & $\begin{array}{c}\text { No. } \\
\text { Urut 02 }\end{array}$ & Jumlah & $\begin{array}{c}\text { Nilai } \\
\text { Eigen } \\
\text { Vektor 1 }\end{array}$ \\
\hline No. Urut 01 & 7,84 & 55,44 & 63,28 & 0,876 \\
No. Urut 02 & 1,11 & 7,84 & 8,95 & 0,124 \\
\hline
\end{tabular}

Perhitungan Normalisasi dengan cara mengurangi hasil Nilai Eigen 1 dengan Nilai Eigen 2.

\begin{tabular}{ccc}
\hline $\begin{array}{c}\text { Nilai Eigen } \\
\text { Vektor } 1\end{array}$ & $\begin{array}{c}\text { Nilai Eigen } \\
\text { Vektor } 2\end{array}$ & $\begin{array}{c}\text { Hasil } \\
\text { Normalisasi }\end{array}$ \\
\hline 0,876 & 0,876 & 0,000 \\
0,124 & 0,124 & 0,000 \\
\hline
\end{tabular}

Karena selisih antara nilai eigen 1 dengan nilai eigen 2 menunjukkan tidak ada perbedaan, maka pencarian nilai eigen 3 tidak perlu dilakukan hal ini menyatakan bahwa hasil nomalisasi telah memnuhi syarat. Untuk hasil prioritas kriteria Kompetensi (KT) terhadap alternatif No. Urut 01 dan No. Urut 02 dapat dilihat pada tabel berikut:

Tabel 24. Prioritas kriteria Kompetensi (KT)

\begin{tabular}{cllll} 
Kompetensi & \multicolumn{1}{c}{ No. } & No. & Nilai & Prioritas \\
$(\mathrm{KT})$ & Urut 01 & Urut 02 & Eigen & $(\%)$ \\
No. Urut 01 & 1,00 & 7,00 & 0,876 & 87,6 \\
No. Urut 02 & 0,14 & 1,00 & 0,124 & 12,4
\end{tabular}

Pada tabel diatas dapat dilihat bahwa untuk pasangan No. Urut 01 memiliki Kompetensi (KT) dengan nilai 87,5\%, sedangkan untuk pasangan No. Urut 02 dengan nilai $12,4 \%$.

Setelah masing-masing bobot dihitung, maka dilakukan pembobotan untuk keseluruhan hasil, hal ini bertujuan untuk mendapatkan sebuah keputusan dalam menentukan pilihan, untuk lebih jelasnya dapat dilihat pada tabel berikut:

Tabel 25. Matrik Berpasangan Seluruh Alternatif

\begin{tabular}{|l|l|l|l|l|l|l|}
\hline & AB & EB & IG & KP & KT & PK \\
\hline No. Urut 01 & 0,857 & 0,857 & 0,876 & 0,856 & 0,856 & 0,876 \\
\hline No. Urut 02 & 0,143 & 0,143 & 0,124 & 0,144 & 0,144 & 0,124 \\
\hline
\end{tabular}

Tabel 26. Nilai Eigen Seluruh Alternatif

\begin{tabular}{|c|}
\hline Nilai Eigen \\
\hline 0,279 \\
\hline 0,075 \\
\hline 0,153 \\
\hline 0,036 \\
\hline 0,437 \\
\hline 0,019 \\
\hline
\end{tabular}

Sehingga didapatkan hasil keseluruhan untuk alternatif, yaitu:

Tabel 27. Hasil Analisis

$\begin{array}{lrr}\text { Alternatif } & \text { Nilai Eigen } & \text { Prioritas (\%) } \\ \text { No. Urut 01 } & 0,859 & 85,9 \% \\ \text { No. Urut 02 } & 0,140 & 14,1 \%\end{array}$

Hasil akhir dari proses analisis matrik perbandingan dengan pembobotan atau prioritas menggunakan metode AHP ini, maka didapatkan hasil bahwa alternatif yang memiliki bobot nilai paling tinggi yaitu pasangan calon dengan Nomor. Urut 01 (Joko Widodo dan Ma'ruf Amin) dengan nilai 85,9\%. sementara pasangan calon dengan nomor urut 02 yaitu Prabowo Subianto dan Sandiaga Uno mendapatkan nilai sebesar $14,1 \%$.

Implementasi Menggunakan Software Super Decisions Adapun langkah yang digunakan dalam proses analisa menggunakan Software Super Decisions, langkah-langkahnya dapat dijelaskan sebagai berikut:

Saat aplikasi Software Super Decisions dijalankan, maka akan muncul menu utama dari aplikasi tersebut seperti yang terlihat pada gambar berikut:

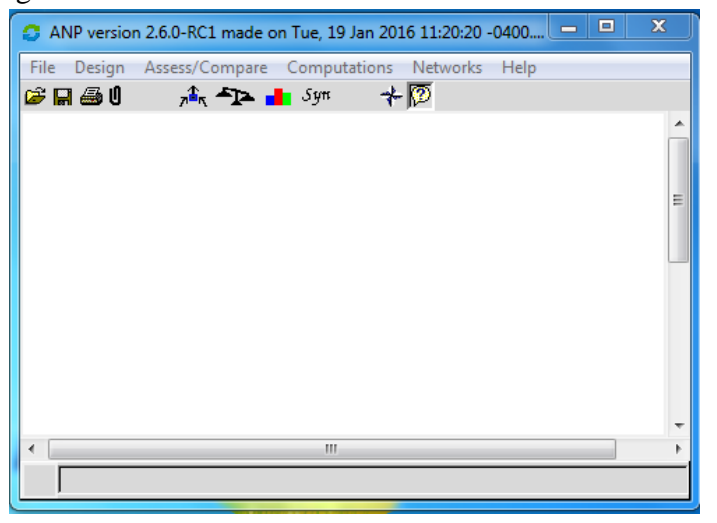

Gambar 4. Tampilan Utama Software Super Decisions Rancang cluster yang digunakan, dalam hal ini cluster yang digunakan adalah cluster GOAL, Kriteria dan Alternatif
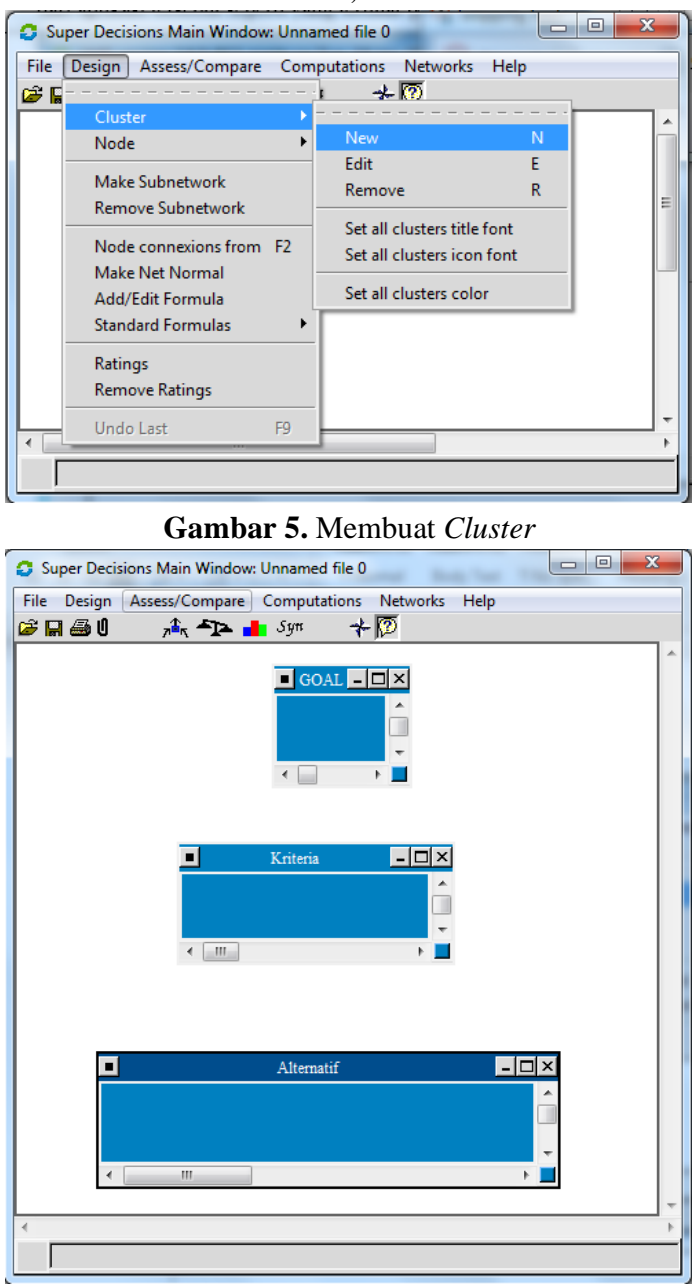

Gambar 6. Cluster yang digunakan

Langkah berikutnya adalah membuat node pada masing-masing cluster, pada cluster GOAL node yang digunakan adalah PRESIDEN 2019, sedangkan pada cluster kriteria, node yang 
digunakan adalah Aspekbilitas, Elektabilitas, Integritas, Kampany, Kompetensi dan Partai Koalisi.

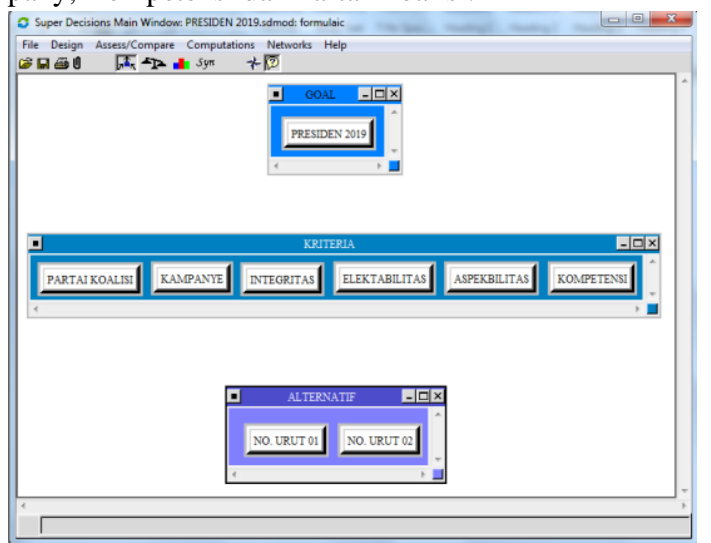

Gambar 7. Pembuatan Node Pada Masing-masing Cluster Setelah semua node dibuat, proses selanjutnya adalah memberikan bobot nilai berdasarkan dari kuesioner yang telah dilakukan proses rekapitulasi sebelumnya. Untuk pengisian kuesioner ini dapat dilakukan dengan mengklik menu Assess/Compare kemudian pilih menu paiwise compartions.

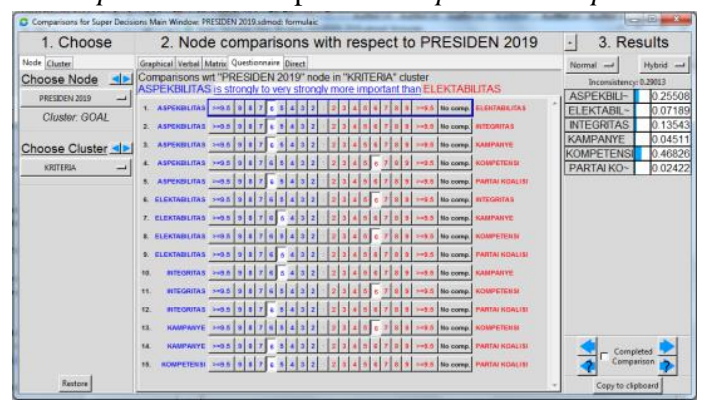

Gambar 8. Pengisian Kuesioner

Klik Matrixs untuk melihat data tersebut dalam bentuk matrik.

\begin{tabular}{|c|c|c|c|c|c|}
\hline Inconsistency & ELEKTABIL & INTEGRTAS $\sim$ & KAMPANYE & KOMPETENSI & PARTAA KOA \\
\hline ASPEKBILT & $\leftarrow$ 目 & $\leftarrow 6$ & $\leftarrow 6$ & $\begin{array}{l}\uparrow \quad 5.9999 \\
\end{array}$ & $\leftarrow 5.9999$ \\
\hline ELEKTABIL & & \begin{tabular}{|l|l|}
$\uparrow$ & 5.9999
\end{tabular} & $\leftarrow 5$ & \begin{tabular}{l|l}
$\uparrow$ & 5.9999 \\
\end{tabular} & $\leftarrow 5$ \\
\hline INTEGRTAS $\sim$ & & & $\leftarrow 5$ & \begin{tabular}{l|l}
$\uparrow$ & 5.9999 \\
\end{tabular} & $\leftarrow 5.9999$ \\
\hline KAMPANYE & & & & \begin{tabular}{l|l}
$\uparrow$ & 5.9999 \\
\end{tabular} & $\leftarrow 5.9999$ \\
\hline KOMPETENSI $~$ & & & & & $\leftarrow 5.9999$ \\
\hline
\end{tabular}

Gambar 9. Tampilan Kuesioner dalam Bentuk Matrik Setelah semua data diinputkan, untuk melihat hasil analisis delakukan dengan meng-klik menu Computations, pilih Syntheisze.

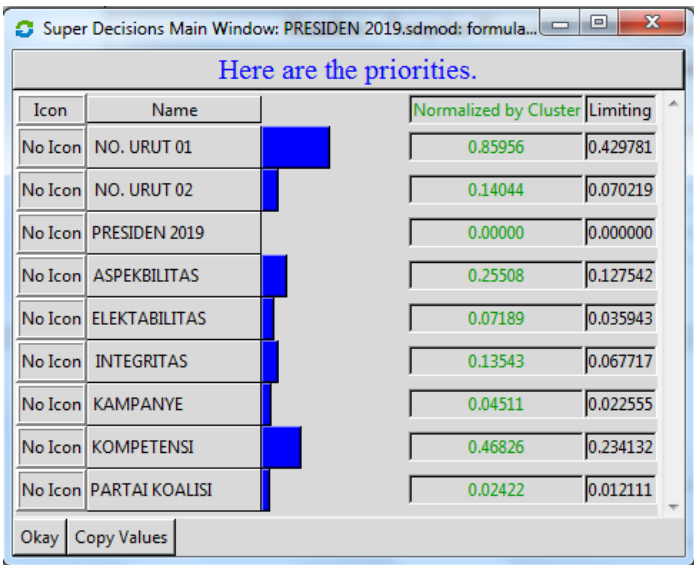

Gambar 10. Hasil Analisa Keseluruhan

\section{CONCLUSIONS}

Dari proses analisa yang telah dilakukan pada bab sebelumnya dalam menentukan pilihan Presiden 2019 menggunakan metode AHP, maka dapat diambil beberapa kesimpulan, yaitu:

1. Penggunaan model Sistem Pendukung Keputusan dalam pemilihan Presiden 2019 menggunakan metode AHP mempunyai beberapa kriteria yaitu: Aspekbilitas (AB), Elektabilitas (EB), Integritas (IG), Kampanye (KP), Kompetensi (KT) dan Partai Koalisi (PK). Sedangkan alternatif yang digunakan adalah Pasangan Calon dengan nomor urut 01 yaitu Joko Widodo dan Ma'ruf Amin dan Pasangan Calon dengan nomor urut 02 yaitu Prabowo Subianto dan Sandiaga Uno.

2. Hasil perhitungan menggunakan matrik perbandingan berpasangan untuk penggunaan kriteria menunjukkan bahwa prioritas yang paling utama ditunjukkan pada Kompetensi (KT) sebesar 46,82\%, prioritas kedua yaitu Aspekbilitas (AB) sebesar 25,50, prioritas ketiga yaitu Integritas (IG) sebesar $13,54 \%$, prioritas keempat yaitu Elektabilitas (EB) Sebesar 7,19\%, prioritas kelima yaitu Kampanye (KP) Sebesar 4,51\% dan prioritas keenam yaitu Partai Koalisi (PK) sebesar 2,42\%. Sedangkan untuk penggunaan alternatif diperoleh data yaitu bobot nilai paling tinggi yaitu pasangan calon dengan Nomor. Urut 01 (Joko Widodo dan Ma'ruf Amin) dengan nilai 85,9\%. sementara pasangan calon dengan nomor urut 02 yaitu Prabowo Subianto dan Sandiaga Uno mendapatkan nilai sebesar $14,1 \%$.

3. Metode AHP dapat digunakan sebagai acuan dalam pemilihan Presiden 2019 di Kota Batam.

4. Sistem Pendukung Keputusan ini digunakan hanya sebagai sistem pendukung dalam pengambilan keputusan, bukan untuk menggantikannya secara keseluruhan.

\section{REFERENCES}

Astradanta, M., Wirawan, I. M. A., \& Arthana, I. K. R. (2016). Pengembangan Sistem Penunjang Keputusan Pemilihan Tempat Kuliner Dengan Menggunakan Metode AHP Dan SAW. Pendidikan Teknik Informatika, 5(Sistem Pendukung Keputusan), 1-11. https://doi.org/10.5395/rde.2015.40.2.172

Balubaid, M., \& Alamoudi, R. (2015). Application of the Analytical Hierarchy Process (AHP) to Multi-Criteria Analysis for Contractor Selection. American Journal of Industrial and Business Management, 5(5), 581-589. https://doi.org/10.4236/ajibm.2015.59058

Dalalah Doraid, F aris Al-oqla, Hayajneh, M. (2010). Application of the Analytic Hierarchy Process ( $A H P$ ) in MultiCriteria Analysis of the Selection of Cranes. Jordan Journal of Mechanical and Industrial Engineering, 4(5), $567-578$

Faisal, \& Permana, S. D. H. (2015). Kejuruan Teknik Komputer Dan Jaringan Yang Terfavorit Dengan Menggunakan Multi-Criteria Decision Making. Urnal Teknologi Informasi Dan Ilmu Komputer (JTIIK), 2(1), 11-19.

Gracia Febrina Lumentut, Julia T Pantow, G. J. W. (2017). Pola Komunikasi Organisasi dalam meningkatkan Motivasi kerja anggota di lpm, $V I(1)$.

Ho, W. (2008). integrated a nalytic hierarchy process and its applications, (ii).

Indonesia, R. (2003). Undang-Undang Republik Indonesia Nomor 12 Tahun 2003 Tentang Pemilihan Umum Anggota Dewan Perwakilan Rakyat, Dewan Perwakilan Daerah, 
Dan Dewan Perwakilan Rakyat Daerah.

Ngatawi, I. S. (2011). Analisis Pemilihan Supplier Menggunakan Metode Analytic Hierarchy Process. Jurnal Ilmiah Teknik Industri, 10(1), 7-13.

Omkarprasad S. Vaidya, S. K. (2013). Analytic hierarchy process: An overview of applications. Biotechnology, Agronomy and Society and Environment, 17(2), 312-320. https://doi.org/10.1016/j.ejor.2004.04.028

Putri, C. F. (2012). Pemilihan Supplier Bahan Baku Pengemas Dengan Metode AHP. Widya Teknika, 20(1), 25-31.

Rimantho, D., Fathurohman, F., Cahyadi, B., \& Sodikun, S. (2017). Pemilihan Supplier Rubber Parts Dengan Metode Analytical Hierarchy Process Di PT.XYZ. Jurnal Rekayasa Sistem Industri, 6(2), 93. https://doi.org/10.26593/jrsi.v6i2.2094.93-104

Rosiska, E. (2018). Penerapan Metode Analitycal Hierarchy Process (AHP) dalam Menentukan Mitra Usaha Berprestasi. Jurnal RESTI (Rekayasa Sistem Dan Teknologi Informasi) , 2(2), 479-485. https://doi.org/https://doi.org/10.29207/resti.v2i2.419

Saefudin, \& Wahyuningsih, S. (2014). Sistem Pendukung Keputusan Untuk Penilaian Kinerja Pegawai Menggunakan Metode Analytical Hierarchy Process (Ahp) Pada RSUD Serang. Jurnal Sistem Informasi, 1(1), 33.

Sasongko, A., Fitri Astuti, I., Maharani, S., Studi Ilmu Komputer, P., Ilmu Komputer dan Teknologi, F., Kunci, K., \& Karyawan Baru, P. (2017). Pemilihan Karyawan Baru Dengan Metode Ahp (Analytic Hierarchy Process). Jurnal Informatika Mulawarman, 12(2), 1858-4853. https://doi.org/10.17605/OSF.IO/Z3R58

Sujaini, H., Pratiwi, H. S., \& Sofhian. (2016). Sistem Pendukung Keputusan Pemilihan Dosen Terbaik Menggunakan Metode Promethee ( Studi Kasus: Teknik Informatika Universitas Tanjungpura ). Jurnal Sistem Dan Teknologi Informasi (JUSTIN), 1(1), 1-6.

Viarani, S. O., \& Zadry, H. R. (2015). Analisis Pemilihan Pemasok dengan Metode Analitycal Hierarchy Process di Proyek Indarung VI PT Semen Padang. Jurnal Optimasi Sistem Industri, 14(1), 55-70. https://doi.org/20884842NOMENCLATURE

\section{AUTHOR(S) BIOGRAPHY}

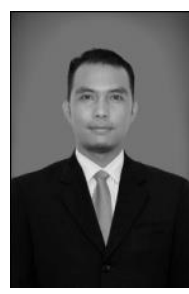

\section{Evan Rosiska}

Lulus S1 di Program Studi Sistem Komputer Fakultas Ilmu Komputer Universitas Putra Indonesia "YPTK" Padang Tahun 2009, lulus S2 di Program Magister Ilmu Komputer Konsentrasi Teknologi Informasi Universitas Putra Indonesia "YPTK" Padang Tahun 2012. Saat ini menjadi dosen pada Prodi Sistem Informasi pada Universitas Putera Batam. 